\title{
Peramalan Jumlah Populasi Sapi Potong di Kalimantan Selatan Menggunakan Metode Moving Average, Exponential Smoothing dan Trend Analysis
}

\author{
Forecasting of Beef Cattle Population Using Moving Average, Exponential Smoothing \\ and Trend Analysis Methods \\ Jaka Darma Jaya ${ }^{1}$ \\ ${ }^{1}$ Jurusan Teknologi Industri Pertanian, Politeknik Negeri Tanah Laut, Jl. A. Yani, Km.6, \\ Desa Panggung, Kec. Pelaihari, Kab. Tanah Laut, Kalimantan Selatan 70815, Indonesia \\ Email Korespondensi: jaka.dj@politala.ac.id
}

Naskah diterima: 11 April 2019; Naskah disetujui : 15 Mei 2019

\begin{abstract}
The development of beef production in Indonesia over the past 30 years has generally tended to increase. The need for beef in Indonesia still cannot be fulfilled by domestic supply, so it is necessary to import beef from abroad. Study is needed on the forecasting availability of beef cattle population in the future so that the government can take appropriate policies in maintaining the stability and fulfillment of national meat supply. This study was aimed to compare the population forecasting of beef cattle population using 3 (three) time series forecasting methods, i.e moving average, exponential smoothing and trend analysis methods. The accuracy of forecasting was measured using MAD (Mean Absolute Deviation), MSE (Mean Squared Error) and MAPE (Mean Absolute Percentage Error). The projection of beef cattle population in 2019 (the next period) using 3 forecasting methods was sequentially 195,100 for moving average; 218,225 for exponential smooting and 262,899 for trend analysis methods. Accuracy measurement using MAD, MSE and MAPE showed that the most accurate forecasting method for beef cattle population was forecasting using the polynomial trend analysis method (MAD 14,716.12; MSE 327,282,084.17; and MAPE 0.09) because it has smaller error rate compared with forecasting results with moving average and exponential smoothing methods.
\end{abstract}

Keywords: beef cattle, forecasting, moving average, exponential smoothing, trend analysis

\begin{abstract}
ABSTRAK
Perkembangan produksi daging sapi di Indonesia selama 30 tahun terakhir secara umum cenderung meningkat. Kebutuhan daging sapi di Indonesia masih belum bisa dicukupi oleh supply domestik, sehingga diperlukan impor daging sapi dari luar negeri. Diperlukan kajian tentang proyeksi ketersediaan populasi sapi potong di masa mendatang agar diambil kebijakan yang tepat dalam menjaga stabilitas dan keterpenuhan supply daging nasional. Penelitian ini bertujuan untuk membandingkan peramalan jumlah populasi sapi potong menggunakan 3 (tiga) metode peramalan time series yaitu metode moving average, exponential smoothing dan trend analysis. Akurasi peramalan
\end{abstract}


selanjutnya diukur menggunakan MAD (Mean Absolud Deviation), MSE (Mean Squared Error) dan MAPE (Mean Absolute Percentage Error). Proyeksi populasi sapi potong pada tahun 2019 (periode berikutnya) menggunakan 3 metode peramalan adalah: 195.100 (moving average); 218.225 (exponential smooting) dan 262.899 (trend analysis). Pengukuran akurasi menggunakan MAD, MSE dan MAPE menunjukkan bahwa metode peramalan jumlah populasi sapi potong yang paling akurat adalah peramalan menggunakan metode polynomial trend analysis (MAD 14.716,12; MSE 327.282.084,17; dan MAPE 0,09) karena memiliki tingkat kesalahan yang lebih kecil dibandingkan hasil peramalan menggunakan metode moving average dan exponential smoothing.

Kata kunci: sapi potong, peramalan, moving average, exponential smoothing, trend analysis

\section{PENDAHULUAN}

Perkembangan produksi daging sapi di Indonesia selama 30 tahun terakhir secara umum cenderung meningkat dengan nilai rata-rata sebesar 2,76\% per tahun (Kementan, 2016). Produk daging sapi adalah komoditas strategis nasional dan kedua paling besar setelah unggas. Kontribusi daging sapi terhadap kebutuhan daging nasional mencapai $23 \%$ dan diperkirakan akan terus meningkat seiring dengan meningkatnya jumlah penduduk Indonesia serta kesadaran untuk mengkonsumsi makanan berprotein tinggi (Kusnadi, 2008). Secara umum kebutuhan daging sapi masih belum dapat sepenuhnya dipenuhi dari supply domestik sehingga perlu dilakukan impor daging maupun sapi bakalan. Hal ini menjadikan Indonesia sebagai negara pengimpor produk daging sapi yang cenderung meningkat dari tahun ke tahun. Begitu juga halnya dengan kebutuhan daging sapi di Kalimantan Selatan yang meningkat dari tahun ke tahun. Kebutuhan daging sapi yang mencapai 3600 kwintal per tahun hanya bisa dipenuhi sepertiganya dari supply lokal. Selebihnya kebutuhan daging sapi ini didatangkan dari Nusa Tenggara Timur, Madura dan Bali.

Tingginya kebutuhan konsumsi daging ini menjadikan sapi potong menjadi salah satu komoditas penting yang mempengaruhi aspek sosial dan ekonomi bangsa Indonesian. Oleh karena itu diperlukan proyeksi produksi ke depan agar pemerintah dan pengusaha dapat mengambil kebijakan yang tepat agar ketersediaan daging sapi bisa stabil di pasaran. Selain itu, bagi pengusaha proyeksi ini juga dapat dijadikan acuan dalam perencanaan produksi sapi potong dalam memenuhi kebutuhan pasar.

Proyeksi populasi dan daging sapi dapat dilakukan melalui proses peramalan. Hal ini dilakukan untuk meminimalisir bias hasil proyeksi, sehingga data proyeksi 
produksi dapat digunakan sebagai pertimbangan dalam pengambilan keputusan. Penelitian terdahulu menunjukkan bahwa metode peramalan telah dilakukan pada komoditas peternakan dan pertanian seperti rempah-rempah (Fauzi, 2016), kopi (Tantika, et al., 2018), padi (Pratama \& Salamah, 2018; Lestari, et al., 2017), Kedelai (Nugraha, et al., 2019), bawang merah (Jatmiko, et al., 2017), ayam potong (Puspitasari \& Afianto, 2017) dan sapi potong (Revi, et al., 2018). Khusus untuk peramalan sapi potong, penelitian terdahulu berfokus pada produksi daging (bukan populasi sapi) dan belum memperbandingkan penggunaan beberapa metode peramalan time series sebagaimana dilakukan pada penelitian ini. Penelitian ini bertujuan untuk membandingkan hasil peramalan populasi sapi potong menggunakan 3 (tiga) metode time series forecasting yaitu metode moving average, exponential smoothing dan trend analysis. Akurasi hasil peramalan akan diukur menggunakan MAD (Mean Absolud Deviation), MSE (Mean Squared Error) dan MAPE (Mean Absolute Percentage Error).

\section{METODE PENELITIAN}

\section{Pengumpulan Data}

Data jumlah sapi potong di Kalimantan Selatan tahun 2009-2018 diperoleh dari data Badan Pusat Statistik Republik Indonesia. Data selanjutnya dianalisis dan diukur akurasinya menggunakan beberapa metode yang ditentukan.

\section{Peramalan Populasi Sapi Potong}

Peramalan jumlah populasi sapi potong dilakukan melalui tiga metode peramalan yang umum digunakan untuk peramalan produk pertanian dan peternakan, yaitu Moving Average, Exponential Smoothing dan Trend Analysis.

\section{a. Metode Moving Average}

Aplikasi metode moving average dalam peramalan dimaksudkan untuk mengurangi acakan dalam deret waktu. Metode moving average dilaksanakan melalui tahapan pengambilan suatu kumpulan nilai yang diobservasi, menghitung rata-rata nilai, dan menggunakannya sebagai ramalan untuk periode selanjutnya (Assauri, 1984; dalam Wardah dan Iskandar, 2016). Perhitungan ramalan melalui metode moving average dilakukan menggunakan rumus berikut.

$$
F_{t+1}=\frac{1}{N} \sum_{i=t-N+1}^{t} X_{i}
$$




\section{Keterangan:}

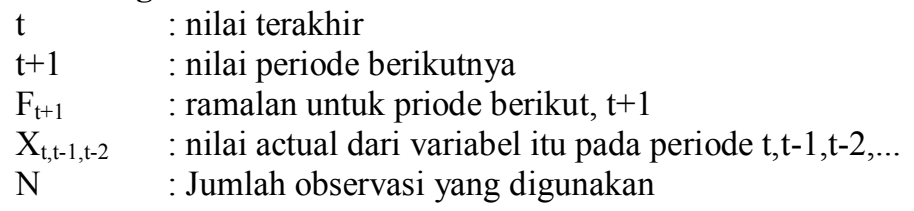

\section{b. Metode Exponential Smoothing}

Metode exponential smoothing dilakukan dengan mengulang perhitungan secara terus menerus menggunakan data terbaru. Setiap data diberi bobot dan disimbolkan dengan $\alpha$. Simbol $\alpha$ bisa ditentukan secara bebas yang bertujuan untuk pemulusan dan mengurangi forecast error (Amelia \& Hairiyah, 2018). Nilai konstanta pemulusan $(\alpha)$ adalah $0<\alpha<1$, dengan rumus peramalan sebagai berikut.

$$
\mathrm{F}_{\mathrm{t}}=\mathrm{F}_{\mathrm{t}-1}+\alpha\left(\mathrm{A}_{\mathrm{t}-1}-\mathrm{F}_{\mathrm{t}-1}\right)
$$

\section{Keterangan: \\ $\mathrm{F}_{\mathrm{t}} \quad$ : nilai ramalan periode waktu ke-t \\ $\mathrm{F}_{\mathrm{t}-1} \quad$ : nilai ramalan periode waktu sebelumnya, $\mathrm{t}-1$ \\ $\mathrm{A}_{\mathrm{t}-1} \quad$ : nilai aktual untuk periode sebelumnya, $\mathrm{t}-1$ \\ $\alpha \quad$ : konstanta pemulusan (smoothing constant)}

c. Metode Trend Analysis

Trend analysis merupakan metode statistik yang bertujuan untuk mencari hubungan sebab akibat antara variabel faktor penyebab atau independen (X) terhadap variabel akibatnya $(\mathrm{Y})$. Trend data dianalisis dan digunakan untuk menentukan peramalan periode berikutnya. Trend pergerakan data tersebut dapat berupa trend linear, polynomial, exponential, logarithmic atau lainnya sesuai dengan pola data yang diolah.

\section{Pengukuran Akurasi Peramalan}

Penilaian terhadap peramalan dilakukan dengan mengamati selisih nilai aktual dengan nilai hasil peramalan. Nilai error adalah perbedaan antara nilai aktual dengan nilai hasil peramalan. Pengukuran akurasi peramalan dilakukan melalui beberapa ukuran yaitu MAD (Mean Absolud Deviation), MSE (Mean Squared Error) dan MAPE (Mean Absolute Percentage Error) (Ishaque \& Ziblim 2013). 


\section{HASIL DAN PEMBAHASAN}

\section{Populasi Sapi Potong di Kalimantan Selatan}

Data produksi yang diolah adalah data populasi sapi potong di Kalimantan selama 10 tahun terakhir dari tahun 2009-2018. Rata-rata populasi sapi potong setiap tahunnya adalah 162.796 ekor. Secara lengkap data populasi sapi potong di Kalimantan Selatan dapat dilihat pada Tabel 1.

Tabel 1. Data Populasi Sapi Potong Tahun 2009-2018

\begin{tabular}{cc}
\hline Tahun Produksi & Populasi Sapi Potong (Ekor) \\
\hline 2009 & 166.825 \\
2010 & 164.219 \\
2011 & 154.147 \\
2012 & 148.296 \\
2013 & 141.446 \\
2014 & 115.235 \\
2015 & 152.495 \\
2016 & 138.691 \\
2017 & 228.545 \\
2018 & 218.065 \\
Jumlah & $\mathbf{1 . 6 2 7 . 9 6 4}$ \\
Rata-Rata & $\mathbf{1 6 2 . 7 9 6}$ \\
\hline Sumber: Badan Pust Statistik (2019)
\end{tabular}

Sumber: Badan Pusat Statistik (2019)

\section{Analisis Peramalan Populasi Sapi Potong}

Data populasi sapi potong pada Tabel 1. Selanjutnya digunakan untuk peramalam jumlah populasi sapi potong pada masa berikutnya. Peramalan pada penelitian dilakukan mengunakan tiga metode yaitu metode moving average, exponential smoothing dan trend analysis. Metode di atas dipilih karena umum diaplikasikan pada peramalam produksi komoditas pertanian dan peternakan (Sari \& Sukojo, 2015; Elvani et al., 2017; Surihadi, 2009; Harvey et al., 2009). 
Tabel 2. Peramalan Jumlah Populasi Sapi Potong

\begin{tabular}{ccccc}
\hline \multirow{2}{*}{ Tahun } & Populasi (ekor) & \multicolumn{3}{c}{ Peramalan Produksi } \\
\cline { 3 - 5 } & & $\begin{array}{c}\text { Moving Average } \\
\text { (3 tahun) }\end{array}$ & $\begin{array}{c}\text { Exponential Smoothing } \\
(\alpha=0,9)\end{array}$ & $\begin{array}{c}\text { Trends Analysis } \\
\text { (polynomial) }\end{array}$ \\
\hline 2009 & 166.825 & - & 162.796 & 180.097 \\
2010 & 164.219 & - & 166.422 & 158.617 \\
2011 & 154.147 & - & 164.439 & 143.751 \\
2012 & 148.296 & 161.730 & 155.176 & 135.499 \\
2013 & 141.446 & 155.554 & 148.984 & 133.859 \\
2014 & 115.235 & 147.963 & 142.200 & 138.833 \\
2015 & 152.495 & 134.992 & 117.931 & 150.419 \\
2016 & 138.691 & 136.392 & 149.039 & 168.619 \\
2017 & 228.545 & 135.474 & 139.726 & 193.433 \\
2018 & 218.065 & 173.244 & 219.663 & 224.859 \\
$2019 *$ & - & $\mathbf{1 9 5 . 1 0 0}$ & $\mathbf{2 1 8 . 2 2 5}$ & $\mathbf{2 6 2 . 8 9 9}$ \\
\hline
\end{tabular}

Keterangan: tanda “*” adalah peramalan periode berikutnya

Berdasarkan peramalan populasi sapi potong (Tabel 2 dan Gambar 1) dapat diketahui bahwa proyeksi populasi sapi potong pada tahun 2019 (periode berikutnya) menggunakan 3 metode peramalan adalah secara berurutan adalah 195.100 (moving average); 218.225 (exponential smooting) dan 262.899 (trend analysis). Untuk menentukan metode peramalan terpilih, data ini selanjutnya diukur menggunakan 3 pengukuran akurasi yaitu MAD, MSE dan MAPE.

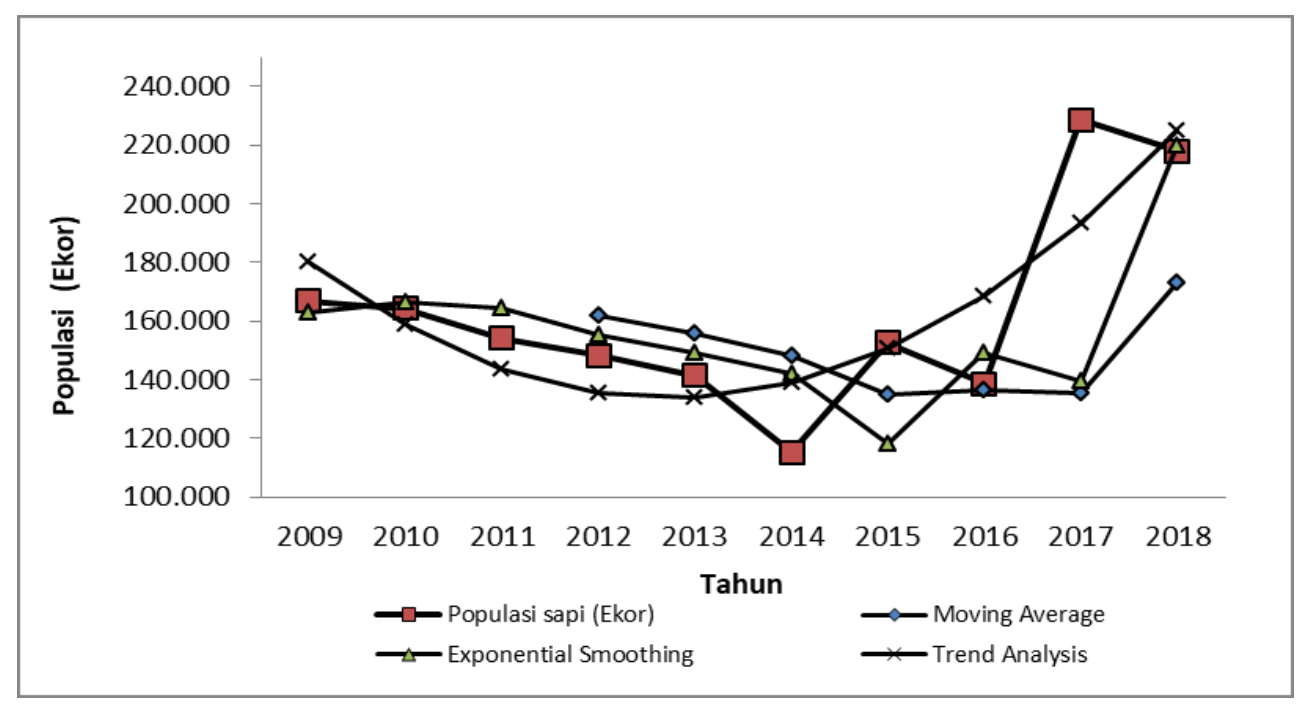

Gambar 1. Hasil Peramalan Populasi Sapi Potong 
Berdasarkan data di atas diketahui bahwa populasi sapi potong di Kalimantan Selatan masih berfluktuasi. Pada rentang tahun 2009-2014 jumplah populasi sapi potong di Kalimantan selatan menurun, hal ini salah satunya disebabkan banyaknya pemotongan sapi betina, yaitu sapi produktif yang diharapkan dapat meningkatkan jumlah populasi sapi secara keseluruhan. Sedangkan pada rentang tahun 2014-2019 cenderung meningkat dikarenakan intensifnya program Upaya Khusus Percepatan Populasi Sapi dan Kerbau Bunting (Upsus Siwab) Kementerian Pertanian RI.

\section{Penentuan Akurasi Peramalan}

Akurasi hasil peramalan ditentukan melalui perhitungan perbedaan hasil peramalan dengan kondisi aktual pengamatan (Wardah \& Iskandar, 2017). Pada penelitian ini digunakan 3 (tiga) ukuran akurasi peramalan yaitu MAD (Mean Absolud Deviation), MSE (Mean Squared Error) dan MAPE (Mean Absolute Percentage Error) seperti ditunjukkan pada Tabel 3. Pengukuran menggunakan MAPE menunjukkan bahwa metode peramalan moving average $(\mathrm{MAPE}=0,17$ ) dan exponential smoothing (MAPE= 0,11) memperlihatkan kinerja yang karena memiliki nilai MAPE antara 10\% dan 20\%, sedangkan metode trend analysis memperlihatkan kinerja sangat bagus dengan nilai MAPE dibawah 10\% (MAPE=0,09) (Raharja et al., 2010).

Tabel 3. Akurasi Peramalan Populasi Sapi Potong di Kalimantan Selatan

\begin{tabular}{cccc}
\hline \multirow{2}{*}{ Ukuran Akurasi } & \multicolumn{3}{c}{ Metode Peramalan } \\
\cline { 2 - 4 } & Moving Average & Exponential Smoothing & Trend Analysis \\
\hline MAD & $31.137,81$ & $19.323,56$ & $14.716,12$ \\
MSE & $1.776 .213 .244,54$ & $1.015 .139 .622,00$ & $327.282 .084,17$ \\
MAPE & 0,17 & 0,11 & 0,09 \\
\hline
\end{tabular}

Berdasarkan nilai MAD, MSE dan MAPE di atas, dapat disimpulkan bahwa metode peramalan populasi sapi potong yang paling akurat adalah peramalan menggunakan metode trend analysis, karena memiliki tingkat kesalahan yang lebih kecil dibandingkan peramalan dengan metode moving average dan exponential smoothing.

\section{KESIMPULAN}

Peramalan pertumbuhan populasi sapi potong pada penelitian ini menggunakan 3 (tiga) metode di atas menunjukkan bahwa proyeksi populasi sapi potong pada tahun 2019 
(periode berikutnya) adalah: 195.100 (moving average); 218.225 (exponential smooting) dan 262.899 (trend analysis). Pengukuran akurasi menggunakan MAD, MSE dan MAPE menunjukkan bahwa metode peramalan populasi sapi potong yang paling akurat adalah peramalan menggunakan metode trend analysis, karena memiliki tingkat kesalahan (error) yang paling kecil dibandingkan peramalan dengan metode moving average dan exponential smoothing dengan nilai masing-masing secara berurutan MAD 14.716,12; MSE 327.282.084,17; dan MAPE 0,09.

\section{UCAPAN TERIMA KASIH}

Terimakasih yang mendalam disampaikan kepada Jurusan Teknologi Industri Pertanian Politeknik Negeri Tanah Laut atas dukungan dan fasilitas yang diberikan dalam pelaksanaan penelitian ini.

\section{DAFTAR PUSTAKA}

Amalia, R. R., \& Hairiyah, N. (2018). Peramalan Kebutuhan Bahan Baku Tandan Buah Segar (TBS) Menggunakan Metode Exponential Smoothing dan Linier Regresion di PT. Pola Kahuripan Intisawit. Jurnal Teknologi Agro-Industri, 5(2), 101-109.

Badan Pusat Statistik (2019). Populasi Sapi Potong menurut Provinsi, 2009-2018. https://www.bps.go.id/linkTableDinamis/view/id/1016 diakses tanggal 1 April 2019.

Elvani, S. P., Utary, A. R., \& Yudaruddin, R. (2017). Peramalan jumlah produksi tanaman kelapa sawit dengan menggunakan metode ARIMA (Autoregressive Integrated Moving Average). Jurnal Manajemen, 8(1), 95-112.

Fauzi, M. (2016). Peramalan Permintaan Produk Rempah-Rempah Menggunakan Metode Jaringan Syaraf Tiruan Dan Time Series Pada PT Supa Surya Niaga Gedangan, Sidoarjo (Doctoral dissertation, Universitas Brawijaya).

Harvey, F. I. W., Januar, J., \& Kusmiati, A. (2009). Trend Produksi dan Prospek Pengembangan Komoditas Buah Naga di Kabupaten Jember. JSEP (Journal of Social and Agricultural Economics), 3(2), 71-78.

Ishaque, M., \& Ziblim, S. (2013). Use of Some Exponential Smoothing Models in Forecasting Some Food Crop Prices in the Upper East Region of Ghana. Mathematical Theory and Modeling, 3(7), 16-27.

Jatmiko, Y. A., Rahayu, R. L., \& Darmawan, G. (2017). Perbandingan Keakuratan Hasil Peramalan Produksi Bawang Merah Metode Holt-Winters dengan Singular Spectrum Analysis (SSA). Jurnal Matematika" MANTIK", 3(1), 13-22. 
Kementerian Pertanian RI. (2016). Outlook Daging Sapi. Jakarta: Pusat Data dan Sistem Informasi Pertanian.

Kusnadi, U. (2008). Inovasi teknologi peternakan dalam sistem integrasi tanaman-ternak untuk menunjang swasembada daging sapi. Pengembangan Inovasi Pertanian, 1(3), 189-205.

Lestari, K. I., Soemartini, S., \& Pontoh, R. S. (2017, November). Penggunaan Metode Fuzzy Time Series Untuk Meramalkan Hasil Produksi Padi Kabupaten Majalengka. In Prosiding Seminar Nasional Statistika| Departemen Statistika FMIPA Universitas Padjadjaran (Vol. 6, No. 1, pp. 203-213).

National Research Council. (1993). Managing Global Livestock Resources. Commitee on Managing Global Genetic Resources. Agricultural Imperatives. National Academic Press, Washington DC, USA. 163 pp.

Nugraha, D., Wardana, I. P., \& Adnyana, M. O. (2019). Ketersediaan Kedelai Berdasarkan Peramalan Produksinya dan Beberapa Kendala serta Permasalahannya di Indonesia. Jurnal Penelitian Pertanian Tanaman Pangan, 2(3), 155-163.

Pratama, A., \& Salamah, S. (2018). Implementasi Sistem Informasi Peramalan Single Expoenential Smoothing Dalam Melihat Kebutuhan Stok Padi di Dinas Pertanian Aceh Utara. Jurnal Sistem Informasi, 2(2).

Puspitasari, D. I., \& Afianto, M. A. (2017). Implementasi Fuzzy Time Series Markov Chain Model (FTSMCM) Dalam Prediksi Jumlah Produksi Ayam Potong. Jurnal Teknologi Informasi Universitas Lambung Mangkurat (JTIULM), 2(2), 14-20.

Raharja, A., Angraeni, W., \& Vinarti, R. A. (2010). Penerapan Metode Exponential Smoothing Untuk Peramalan Penggunaan Waktu Telepon Di PT. Telkomsel Divre3 Surabaya. Jurnal Sistem Informasi.

Revi, A., Solikhun, S., \& Safii, M. (2018). JARINGAN SYARAF TIRUAN DALAM MEMPREDIKSI JUMLAH PRODUKSI DAGING SAPI BERDASARKAN PROVINSI. KOMIK (Konferensi Nasional Teknologi Informasi dan Komputer), 2(1).

Sari, V. D., \& Sukojo, B. M. (2015). Analisa Estimasi Produksi Padi Berdasarkan Fase Tumbuh dan Model Peramalan Autoregressive Integrated Moving Average (ARIMA) Menggunakan Citra Satelit Landsat 8 (Studi Kasus: Kabupaten Bojonegoro). Geoid, 10(2), 194-203.

Surihadi, A. A. (2009). Penerapan Metode Single Moving Average Dan Exponential Smoothing Dalam Peramalan Permintaan Produk Meubel Jenis Coffee Table Pada Java Furniture Klaten (Doctoral dissertation, UNIVERSITAS SEBELAS MARET). 
Tantika, H. N., Supriadi, N., \& Anggraini, D. (2018). Metode Seasonal ARIMA untuk Meramalkan Produksi Kopi Dengan Indikator Curah Hujan Menggunakan Aplikasi R di Kabupaten Lampung Barat. Matematika, 17(2).

Wardah, S., \& Iskandar, I. (2017). Analisis Peramalan penjualan Produk Keripik Pisang Kemasan Bungkus (Studi Kasus: Home Industry Arwana Food Tembilahan). J@ti Undip: Jurnal Teknik Industri, 11(3), 135-142. 